\title{
Antibodies to Acetylcholine Receptor in Parous Women with Myasthenia: Evidence for Immunization by Fetal Antigen
}

\author{
Ian Matthews, Gary Sims, Serena Ledwidge, David Stott, David Beeson, \\ Nick Willcox, and Angela Vincent \\ Neurosciences Group (IM, SL, DB, NW, AV), Weatherall Institute of Molecular Medicine, John Radcliffe Hospital,
Oxford OX3 9DS, and Department of Immunology and Bacteriology (GS, DS), University of Glasgow, Glasgow, \\ United Kingdom
}

\begin{abstract}
SUMMARY: The weakness in myasthenia gravis (MG) is mediated by autoantibodies against adult muscle acetylcholine receptors (AChR) at the neuromuscular junction; most of these antibodies also bind to fetal AChR, which is present in the thymus. In rare cases, babies of mothers with MG, or even of asymptomatic mothers, develop a severe developmental condition, arthrogryposis multiplex congenita, caused by antibodies that inhibit the ion channel function of the fetal AChR while not affecting the adult AChR. Here we show that these fetal AChR inhibitory antibodies are significantly more common in females sampled after pregnancy than in those who present before pregnancy, suggesting that they may be induced by the fetus. Moreover, we were able to clone high-affinity combinatorial Fab antibodies from thymic cells of two mothers with MG who had babies with arthrogryposis multiplex congenita. These Fabs were highly specific for fetal AChR and did not bind the main immunogenic region that is common to fetal and adult AChR. The Fabs show strong biases to $\mathrm{VH} 3$ heavy chains and to a single $\mathrm{V}_{\kappa} 1$ light chain in one mother. Nevertheless, they each show extensive intraclonal diversification from a highly mutated consensus sequence, consistent with antigen-driven selection in successive steps. Collectively, our results suggest that, in some cases of MG, initial immunization against fetal AChR is followed by diversification and expansion of B cells in the thymus; maternal autoimmunity will result if the immune response spreads to the main immunogenic region and other epitopes common to fetal and adult AChR. (Lab Invest 2002, 82:1407-1417).
\end{abstract}

$A$ utoimmune disorders collectively cause much suffering and disability. Many are particularly common in women of child-bearing age. The muscle weakness in the majority of patients with myasthenia gravis (MG) results from autoantibodies to the acetylcholine receptor (AChR), which cause AChR loss, mainly by complement-mediated damage to the postsynaptic membrane and/or accelerated AChR degradation (reviewed by Drachman, 1994; Willcox and Vincent, 1988). The AChR consists of two $\alpha$ subunits and one $\beta, \gamma$, and $\delta$ subunit in the fetus (Unwin, 2000). Together, these subunits form a cationspecific ion channel that opens when ACh binds to the two sites at the $\alpha / \delta$ and either the $\alpha / \gamma$ or $\alpha / \epsilon$ interfaces

DOI: 10.1097/01.LAB.0000032379.63784.9C

Received July 2, 2002.

This work was supported by the Association Française contre les Myopathies (AFM), the Wellcome Trust (GS; grant number 054449/Z/98/Z), and the Medical Research Council.

Current address for Ian Matthews, RSR Ltd., Pentwyn, Cardiff, United Kingdom.

Current address for Gary Sims, NIH, NIAMS, 9000 Rockville Pike, Bethesda, Maryland 20892.

Address reprint requests to: Prof. Angela Vincent, Neurosciences Group, Weatherall Institute of Molecular Medicine, John Radcliffe Hospital, Oxford OX3 9DS, United Kingdom. E-mail: angela.vincent@imm.ox.ac.uk
(Unwin, 2000). From about 30 weeks of gestation in humans, the "adult"-specific $\epsilon$ subunit gradually replaces the $\gamma$ subunit (Hesselmans et al, 1993), but the fetal isoform continues to be expressed on rare myoid cells in the adult thymic medulla (Schluep et al, 1987).

Early-onset MG (before age 40; EOMG) shows an approximately $3: 1$ female bias and a strong HLADR3-B8 association. The thymus is apparently an important site of autoimmunization (Bofill et al, 1985; Drachman, 1994; Kornstein et al, 1984; Schluep et al, 1987; Sims et al, 2001; Willcox and Vincent, 1988); thymectomy is often beneficial and, in most cases of EOMG, the thymus is invaded by lymph node-like T-cell areas and germinal centers (GC) (Bofill et al, 1985; Kornstein et al, 1984; Willcox and Vincent, 1988), many of which show AChR specificity (Sims et al, 2001). GC are well-known sites of B-cell memory generation and of antibody diversification by antigen selection of somatic variants (MacLennan, 1994; Sims et al, 2001). Moreover, there is selective activation of thymic plasma cell responses, with spontaneous production of anti-AChR antibodies (Willcox and Vincent, 1988), which show specificities similar to those in the patients' blood (Heidenreich et al, 1988). The antiAChR antibodies in typical MG patients are very heterogeneous (Vincent et al, 1987), and antibodies cloned from the thymus of typical EOMG patients 
show a range of specificities resembling those in the donors' sera (Farrar et al, 1997; Graus et al, 1997; Serrano et al, 1994).

About $8 \%$ of mothers with MG have babies with transient neonatal MG (NMG), and their sera tend to have higher antibody titers against fetal than adult AChR (Vernet der Garabedian et al, 1994), consistent with a role for thymic AChR in inducing their disease. In some rare examples, babies of mothers with MG are born with severe developmental abnormalities, usually described as arthrogryposis multiplex congenita (AMC; reviewed in Hall and Vincent, 2001), which includes multiple joint contractures, hypoplasia of the lungs, other malformations, and often fetal or neonatal death. The serum of these mothers, some of whom are asymptomatic (Vincent et al, 1995), contains antibodies that strongly and very selectively inhibit the AChtriggered ion channel function of fetal AChR (Riemersma et al, 1997). These inhibitory antibodies persist in the maternal circulation and can transfer a similar condition to the pups after injection into pregnant mice (Jacobson et al, 1999a). Interestingly, the first child of mothers of AMC babies is often unaffected and, when present, MG may not be clinically evident in the mother at the time of the first affected birth (Polizzi et al, 2000), suggesting that the maternal immune system may first be sensitized to AChR from the fetus. Moreover, the dominance of fetal AChR-specific antibodies in these women (Riemersma et al, 1997) suggests that the B-cell response might be clonally restricted.

Here we examined the relationship between inhibitory antibodies and parity in patients with MG and then took advantage of the fact that patients with EOMG are treated by thymectomy, providing us with thymic B cells and plasma cells from which to clone and recombine fetal $A C h R-s p e c i f i c$ antibodies. We selected combinatorial Fabs from two mothers with MG and high levels of fetal AChR-specific antibodies, whose babies had severe AMC. These Fabs proved to be strongly biased toward fetal AChR and were each dominated by one clone with extensive somatic diversification from an already highly mutated consensus sequence. These results suggest that the fetus could be responsible for immunizing the mother during pregnancy, with further diversification occurring subsequently in the thymus.

\section{Results}

\section{Antibodies Inhibiting Fetal AChR Function in MG}

We searched our records for women with MG who had had children before their first available serum sample. We found 12 women with generalized MG who had had one to three children each by the time of sampling, which was before thymectomy or immunosuppressive treatment (parous MG; Table 1); in all but one case, MG presented during or after pregnancy. We compared the results with those of 12 women who had not had children at the time of sampling (nonparous MG), 11 male patients with MG, and 12 healthy controls. Two AMC-M sera were used as positive controls. As expected, the age at MG onset was higher in the parous MG than the nonparous MG women (mean \pm SD; $30.7 \pm 7.8$ compared with $19.9 \pm$ 5.3), but there was no substantial difference in the total levels of anti-AChR antibodies on routine testing (22.26 $\pm 10.6 \mathrm{~nm}$ compared with $26.05 \pm 12.7 \mathrm{~nm})$. Male patients with MG were of a similar age to parous females (30.9 \pm 8.4$)$ and with similar anti-AChR values (18.5 \pm 12.7).

To assay the levels of fetal AChR inhibitory antibodies, we measured the effects of the sera on agonistinduced ${ }^{22} \mathrm{Na}$ flux into TE-671 cells. Healthy sera did not inhibit flux appreciably $(0.02 \pm 0.58 \%$ compared with results in Hepes-Locke buffer alone). Inhibition of flux by the parous MG sera was greater than that by the nonparous ( $p=0.023$; Mann-Whitney one-tailed; Fig. 1) or male MG sera. These results suggest that

Table 1. Clinical Details of the Parous Mothers

\begin{tabular}{clcccc}
\hline $\begin{array}{c}\text { Age at onset } \\
\text { of MG }\end{array}$ & $\begin{array}{c}\text { No. children and } \\
\text { time since last birth, } \\
\text { at onset of MG }\end{array}$ & $\begin{array}{c}\text { No. children at } \\
\text { sampling, age } \\
\text { of last child }\end{array}$ & Age at sampling & $\begin{array}{c}\text { AChR titer } \\
(\mathrm{nM})^{\mathrm{a}}\end{array}$ & $\begin{array}{c}\text { Inhibition of } \\
\text { fetal AChR } \\
\text { function } \\
(\%)\end{array}$ \\
\hline $22 \mathrm{yr}$ & $\begin{array}{l}\text { 1 (NMG), } \\
\text { postpartum }\end{array}$ & $1,4 \mathrm{yr}$ & $26 \mathrm{yr}$ & 24.1 & 30 \\
$22 \mathrm{yr}$ & 0, Before pregnancy & $1,6 \mathrm{yr}$ & $33 \mathrm{yr}$ & 34.1 & 28 \\
$35 \mathrm{yr}$ & 3, During pregnancy & $3,2 \mathrm{yr}$ & $36 \mathrm{yr}$ & 2.4 & 24 \\
$27 \mathrm{yr}$ & 2, Not known & 3, Not known & $29 \mathrm{yr}$ & 24.0 & 22 \\
$25 \mathrm{yr}$ & 1, 1 yr & $1,3 \mathrm{yr}$ & $26 \mathrm{yr}$ & 19.9 & 15 \\
$39 \mathrm{yr}$ & 2, Not known & 2, Not known & $41 \mathrm{yr}$ & 10.6 & 4.5 \\
$30 \mathrm{yr}$ & 1, $1 \mathrm{yr}$ & $1,1 \mathrm{yr}$ & $31 \mathrm{yr}$ & 14.2 & 3.8 \\
$31 \mathrm{yr}$ & 1, $5 \mathrm{yr}$ & $3,2 \mathrm{yr}$ & $38 \mathrm{yr}$ & 25.9 & 3.4 \\
$29 \mathrm{yr}$ & 1, Postpartum & $1,<1 \mathrm{yr}$ & $29 \mathrm{yr}$ & 10.2 & 3.2 \\
$32 \mathrm{yr}$ & 2, Postpartum & $2,<1 \mathrm{yr}$ & $33 \mathrm{yr}$ & 40.1 & 2.3 \\
$29 \mathrm{yr}$ & 2, During pregnancy & $3,6 \mathrm{yr}$ & $35 \mathrm{yr}$ & 33.6 & 1.8 \\
$47 \mathrm{yr}$ & 2, 21 yr & $2,23 \mathrm{yr}$ & $49 \mathrm{yr}$ & 20.6 & 0 \\
\hline
\end{tabular}

${ }^{a}$ These values were those obtained in routine screening and will be underestimates in some cases. 


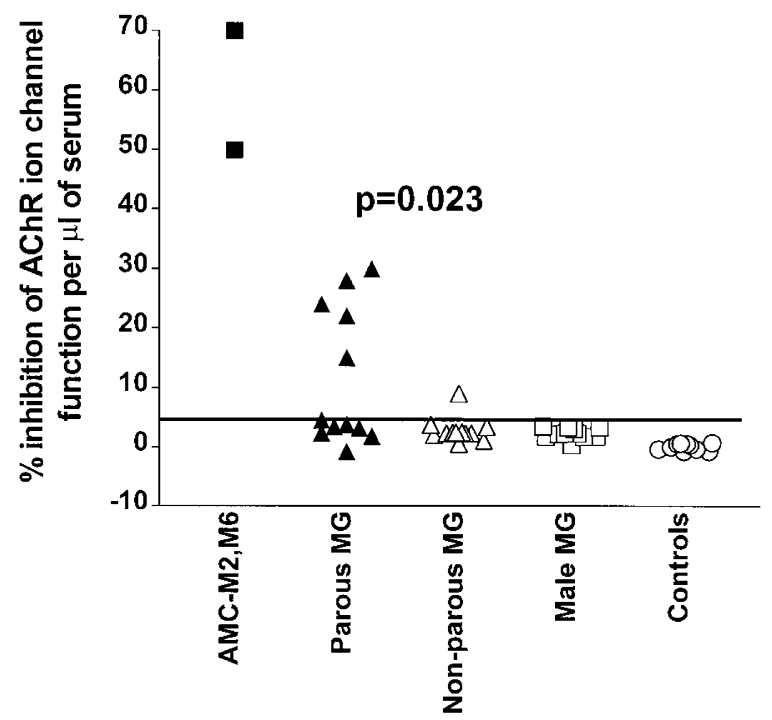

Figure 1.

Inhibition of fetal acetylcholine receptor (AChR) function by sera from AMC-M2 and AMC-M6, from different groups of patients with myasthenia gravis (MG), and from healthy controls. Carbachol-induced ${ }^{22} \mathrm{Na}^{+}$uptake into TE671 cells was measured after preincubation in each of the sera, with dilutions from 1:20 to 1:500. The inhibition of ${ }^{22} \mathrm{Na}^{+}$uptake was expressed as a percent of that obtained in the presence of $\alpha$-bungarotoxin ( $\alpha$-BuTx), an irreversible antagonist of AChR function. Preliminary data were presented by Vincent et al (2001).

pregnancy can influence the specificity of AChR antibodies in patients with MG and may initiate the response in some susceptible individuals.

\section{Cloning Anti-AChR Fabs from Thymic Combinatorial Libraries}

To examine the clonal origins of fetal-specific AChR antibodies, we characterized Fabs cloned from unamplified $\mathrm{VH} / \mathrm{V}_{\kappa}$ cDNA libraries prepared from thymic cells of AMC-M2 and AMC-M6, after screening 2.0 to $2.5 \times 10^{5}$ clones. It was relatively easy to detect AChR-specific plaques by blotting the expressed Fabs with ${ }^{125} \mid-\alpha$-BuTx-AChR solubilized from human muscle and to clone the positives by further rounds of screening (Fig. 2a); the results are summarized in Table 2. Fetal AChR inhibitory antibodies compete with one of the two $\alpha$-bungarotoxin ( $\alpha$-BuTx) binding sites (Riemersma et al, 1997), leaving the second site available for detection with ${ }^{125} \mid-\alpha$-BuTx. Therefore, to clone Fabs that might compete with $\alpha$-BuTx for binding to the fetal AChR, we rescreened the AMC-M2 library with unlabeled muscle extract, allowing the AChR to bind before we applied the ${ }^{125} \mid-\alpha$-BuTx. A further 25 clones were thus isolated, and two were characterized in detail. We also prepared a parallel $\mathrm{VH} / \mathrm{V} \lambda$ library from AMC-M2 and isolated another 25 clones (Table 2).

\section{Specificity of AMC-M Fabs for Fetal AChR}

Both AMC-M2 and AMC-M6 libraries yielded Fabs that efficiently immunoprecipitated ${ }^{125} \mid-\alpha$-BuTx-human AChR, in most cases precipitating all of the (a)

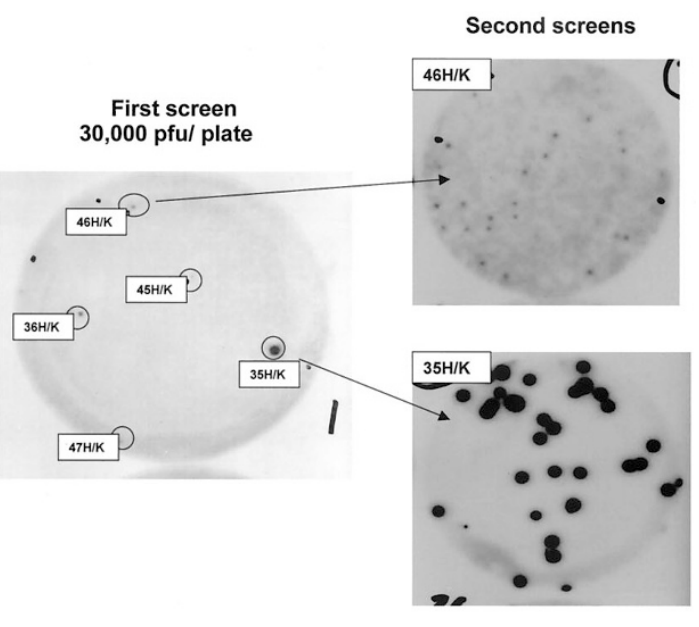

(b)

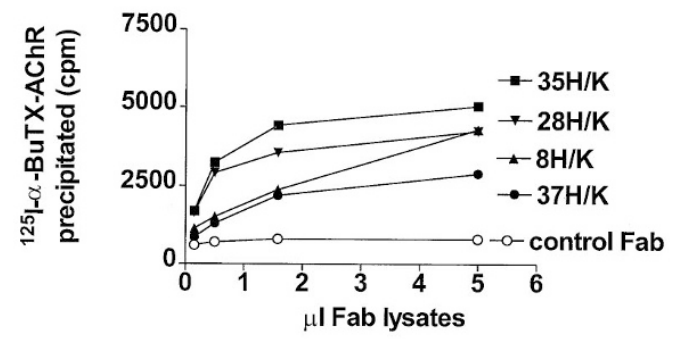

(c)

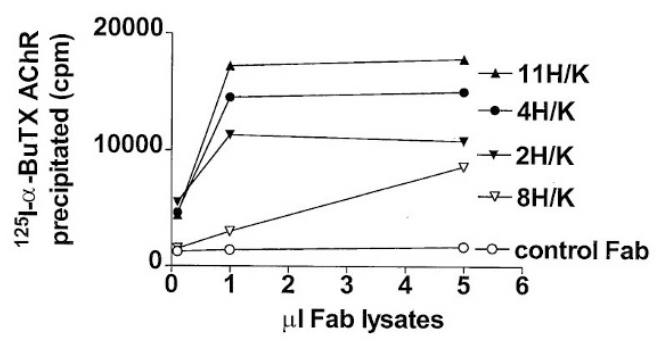

Figure 2.

AChR binding by Fab clones. a, Example of immunoblot plaque lifts to detect Fab clones binding ${ }^{125} \mid-\alpha$-BuTx-AChR extracted from ischemic human leg muscle. Immunoprecipitation of ${ }^{125}-\alpha$-BuTX-AChR by representative cloned Fabs from AMC-M2 (b) and from AMC-M6 (c).

available receptor. Examples of titrations of the Fabs are shown in Figure 2 ( $b$ and $c$ ); the efficient binding by monomeric Fabs of soluble AChR (at $\sim 500$ pm final concentration) indicates a high affinity. The muscle extracts used for screening and precipitations were from amputees with ischemic disease; although these have a preponderance of fetal compared with adult AChR (Vincent and Newsom-Davis, 1985), antibodies to the $\alpha, \beta$, or $\delta$ subunits bind similarly to both isoforms (Fostieri et al, 2000; Tzartos et al, 1998). We therefore tested the Fabs against AChR extracted from TE671 cells that express only fetal AChR or from a TE671 subline that expresses predominantly (>90\%) adult AChR (Beeson et al, 1996). The two AMC-M sera preferred the fetal isoform, although they also showed some reactivity with adult AChR (Fig. 3a). However, all of the Fabs, with one exception (Fab 8H/K from AMC-M6), bound almost exclusively to fetal AChR. Even the low apparent reactivity with the adult 
Table 2. Screening and Derivation of the Anti-AChR Fab Clones

\begin{tabular}{|c|c|c|c|c|c|}
\hline & $\begin{array}{l}\text { No. of clones } \\
\text { screened }\end{array}$ & Screening method & $\begin{array}{l}\text { No. of positives } \\
\text { obtained }\end{array}$ & $\begin{array}{l}\text { No. of clones } \\
\text { isolated }\end{array}$ & Main clones characterized \\
\hline $\begin{array}{l}\text { AMC-M2 } \\
\mathrm{VH} / \mathrm{V}_{\kappa}\end{array}$ & $2.5 \times 10^{5}$ & ${ }^{125} \mathrm{I}-\alpha$-BuTx-AChR & 34 & $25^{a}$ & $\begin{array}{l}8 \mathrm{H} / \mathrm{K}, 10 \mathrm{H} / \mathrm{K}, 13 \mathrm{H} / \mathrm{K}, 28 \mathrm{H} / \mathrm{K}, \\
30 \mathrm{H} / \mathrm{K}, 38 \mathrm{H} / \mathrm{K}\end{array}$ \\
\hline $\begin{array}{l}\text { AMC-M2 } \\
\text { VH/ }{ }_{\kappa}\end{array}$ & $2.5 \times 10^{5}$ & $\begin{array}{l}\text { AChR followed by } \\
{ }^{125} \mid-\alpha \text {-BuTx }\end{array}$ & 17 & 15 & $35 \mathrm{H} / \mathrm{K}, 53 \mathrm{H} / \mathrm{K}$ \\
\hline $\begin{array}{l}\text { AMC-M2 } \\
\text { VH/V } \lambda\end{array}$ & $2.5 \times 10^{5}$ & ${ }^{125} \mid-\alpha$-BuTx-AChR & 29 & $25^{a}$ & $\mathrm{ND}^{b}$ \\
\hline $\begin{array}{l}\text { AMC-M6 } \\
\text { VH/ }{ }_{\kappa}\end{array}$ & $2.0 \times 10^{5}$ & ${ }^{125} \mid-\alpha$-BuTx-AChR & 13 & 10 & $\begin{array}{l}1 \mathrm{H} / \mathrm{K}, 2 \mathrm{H} / \mathrm{K}, 4 \mathrm{H} / \mathrm{K}, 5 \mathrm{H} / \mathrm{K}, 6 \mathrm{H} / \mathrm{K}, \\
\quad 8 \mathrm{H} / \mathrm{K}, 10 \mathrm{H} / \mathrm{K}, 11 \mathrm{H} / \mathrm{K}\end{array}$ \\
\hline
\end{tabular}

\footnotetext{
${ }^{a}$ Preliminary BstXI digests of the $\mathrm{VH} / \mathrm{VL}$ inserts showed that $\sim 80 \%$ of the clones were clearly different; we characterized and sequenced those that grew most readily, as also with clones $35 \mathrm{~K}$ and $53 \mathrm{~K}$ from this patient and with those from AMC-M6.

${ }^{b}$ For AMC-M2 VH/V $\lambda$, the nine complete VH sequences showed near identity to the VH3-07 genes used in this patient's VH/ $\mathrm{V}_{\kappa}$ clones, whereas the $\mathrm{V} \lambda$ genes were heterogeneous (not shown).
}

AChR preparation could be a result of the remaining $10 \%$ of fetal AChR (Beeson et al, 1996).

To confirm this striking finding, we also tested the Fabs' ability to block the binding of mAbs specific for human fetal AChR $\gamma$ subunits. Both AMC-M2 and AMC-M6 serum antibodies blocked binding of each of the two mAbs specific for fetal AChR (Fig. 3, b and c), as did all the Fabs except $8 \mathrm{~K}$ from AMC-M6, which instead blocked binding of the mAb with $\beta$ subunit specificity (Fig. 3c). These experiments confirm the high affinity for fetal AChR of the Fabs and most of the serum antibodies, and their probable $\gamma$ subunit specificity.

It was also important to test the Fabs for inhibition of fetal AChR ion channel function. Disappointingly, only Fab 35K from AMC-M2 showed appreciable activity and that only at relatively high Fab concentrations (50\% inhibition at $100 \mu \mathrm{l}$ of Fab). There was no effect on adult AChR (data not shown). In parallel experiments, cross-linking the cloned Fabs with secondary antibodies did not increase the degree of inhibition. Indeed, inhibition of function did not require divalent antibodies, because it was readily measurable with monovalent Fabs prepared from both donors' serum $\lg$ (not shown).

\section{Sequences of the AMC-M2 Fab VH and Vא Genes}

The $\mathrm{V}$ genes were sequenced and compared with those in the human Ig VBASE directory (Tomlinson et al, 1997) to identify both the closest germline sequence and the number of somatic mutations (Table 3). All the AMC-M2 Fabs were specific for fetal AChR and used the same VH3-07/D?/JH6b combination, regardless of both the screening procedure used to identify them (Table 2) and their exact $\kappa$ (Table 3) or $\lambda$ light chain partner (not shown). They had the same CDR3 length and the majority shared 32 "consensus" VH mutations, demonstrating a common clonal origin from a previously-mutated progenitor. Replacement: silent (R:S) ratios were higher in the first two hypervariable (complementarity-determining region; CDR) loops than in the framework (FWR) regions, strongly suggesting antigen-driven selection for antibody specificity/affinity.

By contrast, the AMC-M2 kappa light sequences were heterogeneous; despite their similar binding specificity, these Fabs used a variety of $V_{\kappa}$ (Table 3 ), which varied substantially both in numbers of mutations and R:S ratios. Although two Fabs used the $V_{\kappa}$ $02 / 12$ gene, their different $J_{\kappa}$ usage demonstrates that they are independent gene rearrangements. This contrasting $\mathrm{VH}$ restriction and $\mathrm{V}_{\kappa}$ diversity suggests that the heavy chain was primarily responsible for the fetal AChR-binding specificity.

\section{Recurring VH and Vк Usage by AMC-M6 Fabs}

Table 3 also summarizes the genes encoding the second donor's anti-AChR Fabs. Fab $8 \mathrm{H} / \mathrm{K}$ is the first human AChR $\beta$ subunit-specific autoantibody to be cloned. It uses the relatively uncommon $\mathrm{VH} 4-61$ gene in combination with the commonly expressed VK1 $02 / 12 V_{\kappa}$ gene. Both the heavy and light chains are highly mutated, with higher R:S ratios in the CDR than the FWR regions (Table 3). One of the fetal AChRspecific Fabs (Fab $1 \mathrm{H} / \mathrm{K}$ ) used a highly mutated VH323/DH3.3/JH6b plus a $V_{\kappa} 4 \mathrm{~B} 3 / \mathrm{J}_{\kappa} 3$ gene (Table 3). All of the others used the same pair of VH3-21/D?/JH5b heavy and $V_{\kappa} 02 / 12$ light chain genes, again with $J_{\kappa} 4$ (Table 3); because the frequency of base differences between these sequences is significantly above the PCR error rate for the Taq polymerase used (Chazenbalk et al, 1993), the VHs and $V_{\kappa s}$ are clearly clonally related.

The extent of somatic mutation shows that each is clearly derived from a highly mutated progenitor (with 44 consensus substitutions in the $\mathrm{VH}$ and 25 in the $\left.V_{\kappa}\right)$. The R:S ratios for the heavy chain gene are moderate because the number of $\mathrm{VH}$ mutations approaches saturation (often two or even three per codon). Their closest germline counterparts and their clonal relationships are shown in Figure 4; the pattern is essentially similar for the $\mathrm{VH}$ sequences of the AMC-M2 Fabs (not shown). In the genealogic trees for both heavy and light chains, the branching patterns, 
(a)
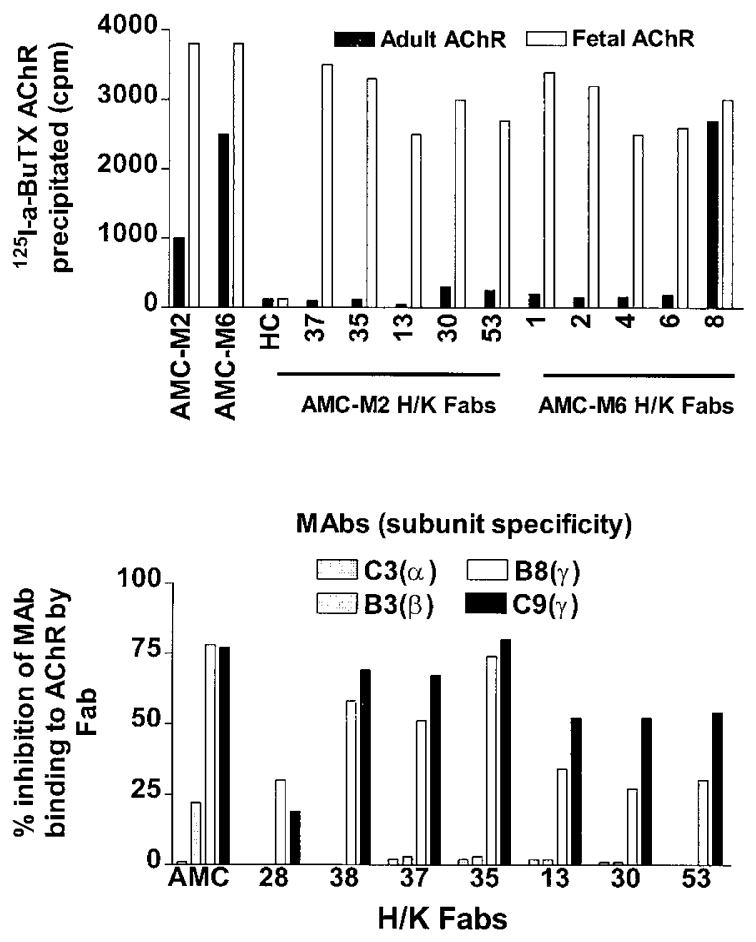

(c)

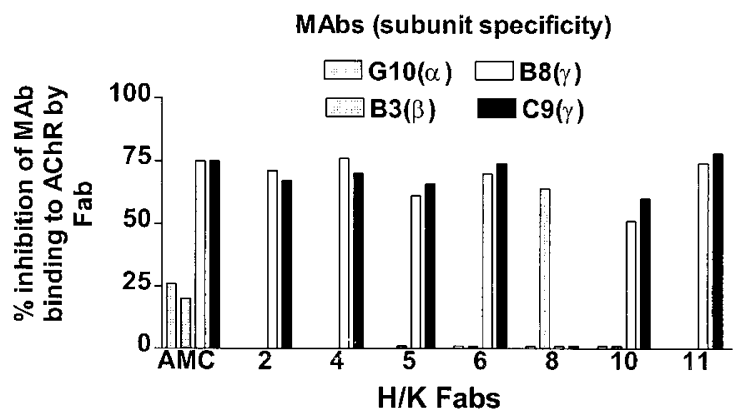

Figure 3.

Specificity of cloned Fabs. a, Reactivity of AMC-M2 and AMC-M6 serum antibodies and representative Fabs with adult and fetal AChR. The AChRs were obtained from TE671 cells (fetal AChR) and from TE671 cells transfected with excess of the AChR $\epsilon$ subunit (providing approximately $90 \%$ adult AChR and $10 \%$ fetal AChR). b, Competition of AMC-M2 serum and Fabs with mAbs directed against the indicated AChR subunit. All of the Fabs inhibited the binding of mAbs specific for the $\gamma$ subunit. c, Competition of AMC-M6 serum (AMC) and Fabs with mAbs, as above. All but one of the Fabs inhibited binding of mAbs specific for the $\gamma$ subunit; the other only inhibited binding to an mAb specific for the $\beta$ subunit. The characterization of the mAbs is detailed in Jacobson et al (1999b).

with variable numbers of successive mutations separating each sequence, are clear evidence of further antigen-driven clonal proliferation and somatic mutation; moreover each stems from an already-mutated progenitor. Notably also, because neither this heavy nor this light chain was found with other partners, they could both be derived from the same progenitor $B$ cell.

\section{Convergent Mutations Suggesting Common Fetal AChR-Specific Selection Processes}

We saw recurring replacements in the three independent fetal AChR-specific VH3 genes and especially in the $V_{\kappa} 02 / 12$ sequences. In brief, there was a CDR1 ${ }^{31} \mathrm{~S} \rightarrow$ T substitution in all VH3 Fabs from AMC-M2 and AMC-M6. Even more strikingly, among the $V_{\kappa} \quad 02 / 12$ light chains, AMC-M2 $13 \mathrm{~K}$ and the majority of the
AMC-M6 Fabs not only use $\mathrm{J}_{\kappa} 4$ but also have common ${ }^{22} \mathrm{~T} \rightarrow \mathrm{S},{ }^{27} \mathrm{Q} \rightarrow \mathrm{E},{ }^{28} \mathrm{~S} \rightarrow \mathrm{T}$, and ${ }^{53} \mathrm{~S} \rightarrow \mathrm{T}$ replacements. The former three contribute to the CDR1 to form a ${ }^{22}$ SRASET ${ }^{28}$ motif that is found in only two other human $\kappa$ sequences in GenBank. Moreover, these recurring $\mathrm{H}$ and $\mathrm{L}$ chain mutations were not seen in another fetal AChR-specific Fab from a nonparous EOMG female (Farrar et al, 1997) or in the very different AChR $\beta$-specific Fab-8 from AMC-M6 (not shown).

\section{Discussion}

We have shown, for the first time, that antibodies inhibiting the ion channel function of fetal AChR are common not only in mothers of babies with AMC (Riemersma et al, 1997) but also in women who 
Table 3. Heavy and Light Chain V Genes Encoding Anti-AChR Fabs

\begin{tabular}{|c|c|c|c|c|c|c|c|c|c|c|}
\hline \multirow[b]{3}{*}{$\mathrm{Fab}$} & \multicolumn{5}{|c|}{ Heavy chain gene } & \multicolumn{4}{|c|}{ Light chain gene } & \multirow{3}{*}{$\begin{array}{c}\text { AChR } \\
\text { specificity }\end{array}$} \\
\hline & \multirow[b]{2}{*}{$V_{H}-D_{H}-J_{H}$ segments } & \multirow{2}{*}{$\begin{array}{l}\text { No. of } \mathrm{V}_{\mathrm{H}} \\
\text { mutations }\end{array}$} & \multicolumn{2}{|c|}{$\mathrm{R}: \mathrm{S}$ ratio } & \multirow{2}{*}{$\begin{array}{c}\text { CDR3 } \\
\text { length }^{a}\end{array}$} & \multirow[b]{2}{*}{$V_{k}-J_{k}$ segments } & \multirow{2}{*}{$\begin{array}{l}\text { No. of } \mathrm{V}_{\mathrm{H}} \\
\text { mutations }\end{array}$} & \multirow{2}{*}{$\frac{\mathrm{R}: \mathrm{S} \text { ratio }}{\text { FWR CDR }}$} & \multirow{2}{*}{$\begin{array}{l}\text { CDR3 } \\
\text { length }\end{array}$} & \\
\hline & & & FWR & $\mathrm{CDR}$ & & & & & & \\
\hline \multicolumn{11}{|l|}{ AMC-M2 } \\
\hline $10 \mathrm{H} / \mathrm{K}$ & VH3-07 D? JH6b & 33 & 1.0 & 12 & 23 & VK1 L5 JK1 & 13 & 1.51 .7 & 9 & Fetal \\
\hline $13 \mathrm{H} / \mathrm{K}$ & VH3-07 D? JH6b & 32 & 0.9 & 12 & 23 & VK1 02/12 JK4 & 33 & $0.9 \quad 1.7$ & 9 & Fetal \\
\hline $30 \mathrm{H} / \mathrm{K}$ & VH3-07 D? JH6b & 32 & 0.9 & 12 & 23 & VK3 L2 JK2 & 2 & $->2$ & 11 & Fetal \\
\hline $28 \mathrm{H} / \mathrm{K}$ & VH3-07 D? JH6b & 33 & 0.5 & 12 & 23 & VK1 L1 JK1 & 2 & $>1<1$ & 9 & Fetal \\
\hline $35 \mathrm{H} / \mathrm{K}^{b}$ & VH3-07 D? JH6b & 34 & 0.5 & 13 & 23 & VK1 02/12 JK1 & 3 & $->3$ & 11 & Fetal \\
\hline $53 \mathrm{H} / \mathrm{K}^{b}$ & VH3-07 D? JH6b & 33 & 0.5 & 12 & 23 & VK2 A3/19 JK4 & 11 & 1.01 .3 & 9 & Fetal \\
\hline $8 \mathrm{H} / \mathrm{K}$ & VH3-07 D? JH6b & 34 & 0.6 & 12 & 23 & VK1 08/18 JK2 & 20 & 2.07 .0 & 9 & Fetal \\
\hline $38 \mathrm{H} / \mathrm{K}$ & VH3-07 D? JH6b & 49 & 1.7 & 3.8 & 23 & VK1 L11 JK1 & $10^{c}$ & 2.01 .3 & 8 & Fetal \\
\hline \multicolumn{11}{|l|}{ AMC-M6 } \\
\hline $8 \mathrm{H} / \mathrm{K}$ & VH4-61*02 DH1-26 JH4b & 36 & 1.0 & $>14$ & 10 & VK1 02/12 JK1 & 16 & $0.2>9$ & 9 & $\begin{array}{l}\text { Adult and } \\
\text { fetal }\end{array}$ \\
\hline $1 \mathrm{H} / \mathrm{K}$ & VH3-23 DH3-3 JH6b & 27 & 1.0 & 2.8 & 14 & VK4 B3 JK3 & 14 & $1.0 \quad 3.0$ & 9 & Fetal \\
\hline $10 \mathrm{H} / \mathrm{K}$ & VH3-21 D? JH5b & 55 & 0.8 & 2.1 & 18 & VK1 02/12 JK4 & 49 & $0.7 \quad 2.3$ & 9 & Fetal \\
\hline $5 \mathrm{H} / \mathrm{K}$ & VH3-21 D? JH5b & 54 & 0.7 & 1.8 & 18 & VK1 02/12 JK4 & 44 & $0.6 \quad 2.3$ & 9 & Fetal \\
\hline $6 \mathrm{H} / \mathrm{K}$ & VH3-21 D? JH5b & 55 & 0.8 & 1.8 & 18 & VK1 02/12 JK4 & 36 & $0.9 \quad 9.0$ & 9 & Fetal \\
\hline $2 \mathrm{H} / \mathrm{K}$ & VH3-21 D? JH5b & 56 & 0.7 & 1.8 & 18 & VK1 02/12 JK4 & 34 & 1.09 .0 & 9 & Fetal \\
\hline $4 \mathrm{H} / \mathrm{K}$ & VH3-21 D? JH5b & 48 & 0.7 & 1.3 & 18 & VK1 02/12 JK4 & 35 & $0.8 \quad 8.0$ & 9 & Fetal \\
\hline $11 \mathrm{H} / \mathrm{K}$ & VH3-21 D? JH5b & 56 & 0.8 & 1.6 & 18 & VK1 02/12 JK4 & 31 & $0.8 \quad 4.0$ & 9 & Fetal \\
\hline
\end{tabular}

\begin{tabular}{|c|c|c|}
\hline & VH CDR3 amino acid sequence ${ }^{d}$ & VK CDR3 amino acid sequences \\
\hline \multicolumn{3}{|l|}{ AMC-M2 } \\
\hline $\begin{array}{l}10,13,30,28, \\
35 \text { and }\end{array}$ & VRRYGPSTLSPFTWKDNHYAMCD & $\begin{array}{l}\text { VK genes unrelated, all VK } \\
\text { CDR3s are different }\end{array}$ \\
\hline $53 \mathrm{H} / \mathrm{K}$ & מ & \\
\hline $38 \mathrm{H} / \mathrm{K}$ & --QF-ALPPNQYNFDEL------ & \\
\hline \multicolumn{3}{|l|}{ AMC-M6 } \\
\hline $8 \mathrm{H} / \mathrm{K}$ & GRGKFELLDF & QQSYNTPNT \\
\hline $1 \mathrm{H} / \mathrm{K}$ & VVNYQRSQVGWFDP & QQYSGFSWT \\
\hline 10 and $5 \mathrm{H} / \mathrm{K}$ & EWGSRFITTFRGLPHFDL & QQSYLTPLT \\
\hline $6 \mathrm{H} / \mathrm{K}$ & ------------------ & ----T---- \\
\hline $2 \mathrm{H} / \mathrm{K}$ & ---------------- & ---FT---- \\
\hline $4 \mathrm{H} / \mathrm{K}$ & --------S---------- & ----T---- \\
\hline $11 \mathrm{H} / \mathrm{K}$ & --------P--------- & ----T---- \\
\hline
\end{tabular}

Heavy and light chain V genes encoding anti-AChR Fabs from AMC-M2 and AMC-M6. H/K refers to the heavy and kappa V gene sequences that have been deposited with GenBank (Accession numbers AY033517-033550).

${ }^{a}$ The length of the CDR3 is given in amino acids; the CDR3 sequences are shown in the bottom half of the table.

${ }^{b}$ Isolated by screening first with unlabeled AChR, followed by $\alpha$-BuTx.

${ }^{c}$ The 10 VK mutations do not include a three-base insertion at the end of CDR1 at AA35 that encodes a leucine residue.

${ }^{d}$ Among the related Fabs, only the amino acid differences are shown.

developed MG after pregnancy. By contrast, such antibodies were uncommon in women who presented before pregnancy. In addition, the many high-affinity Fabs that we cloned from the thymus of two AMC mothers showed a very strong preference for fetal AChR and a biased usage of $\mathrm{VH} 3$ genes. The striking diversification of the Fabs in each woman from a common, but already highly mutated, germ-line sequence, shows that the autoantibodies can arise via successive rounds of antigen-driven selection in a few clones. These results suggest a scenario in which oligoclonal responses to fetal AChR, including some that block fetal AChR function, are the initiating event in women who develop MG after pregnancy, irrespective of whether the level of these antibodies is sufficient to cause AMC. Immunization by the fetus is, therefore, another possible contributory factor to the female bias evident in many autoimmune diseases, in addition to the established hormonal influences (Whitacre, 2001) and the possible roles of fetal $\leftrightarrow$ maternal microchimerism (Hall et al, 1995; Maloney et al, 1999; Nelson, 2001).

The Fabs that we cloned from the two unrelated AMC mothers show remarkable similarities. They clearly have high affinities because they immunoprecipitate AChR at $\sim 500 \mathrm{pm}$ and, despite being monomeric, they also efficiently block binding of bivalent mAbs. In theory, the predominance of fetal AChR in the ischemic muscle extracts we used (Vincent and Newsom-Davis, 1985) might have created a bias in screening toward fetal AChR-binding Fabs. However, the main immunogenic region (MIR) on the $\alpha$ subunits 


VH3-21
AMC-M6 10H
AMC-M6 5H
AMC-M6 6H
AMC-M6 2H
AMC-M6 4H
AMC-M6 11H

vH3-21

AMC-M $10 \mathrm{H}$

AMC-M6 5H

AMC-M6 6H

AMC-M6 2H

AMC-M6 4H

AMC-M6 11H

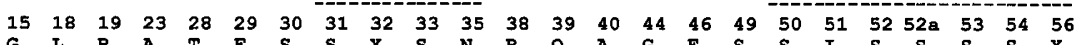
$\begin{array}{ccccccccccccccccccccc}G & & & \end{array}$

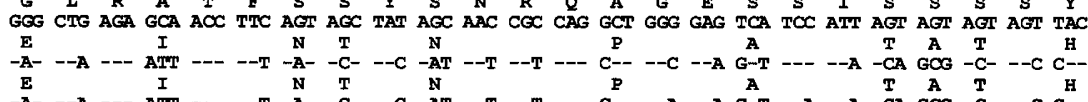

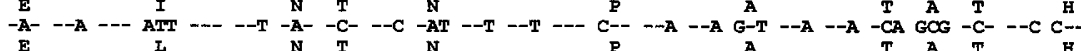

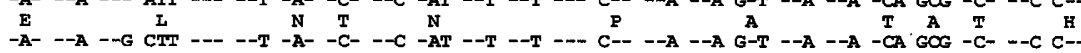

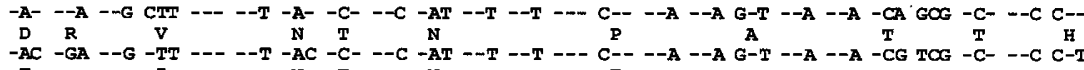

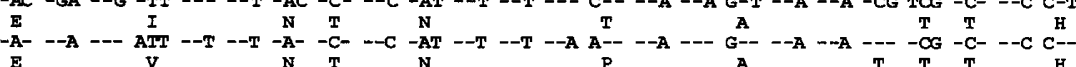

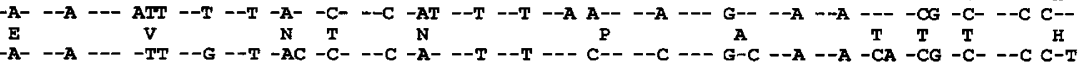
CDR2 cont.

$\begin{array}{lllllllllllllllllllllll}57 & 58 & 59 & 60 & 61 & 62 & 63 & 64 & 65 & 66 & 68 & 74 & 76 & 77 & 78 & 80 & 81 & 83 & 84 & 88 & 91 & 92 & 94\end{array}$

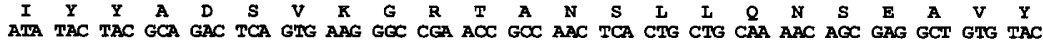

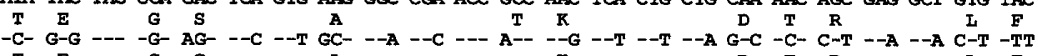

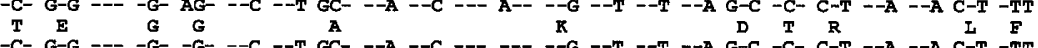

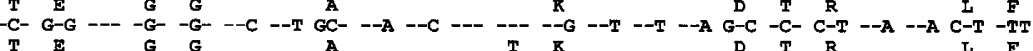

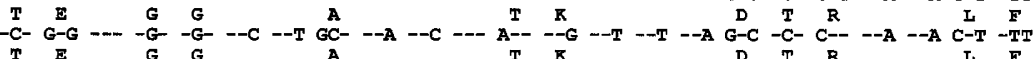

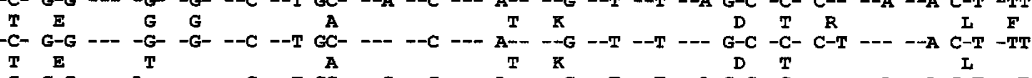
-C- G-G --- A-- --- --C --T GC-

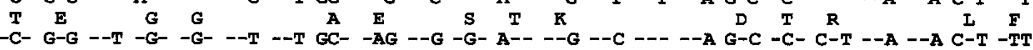

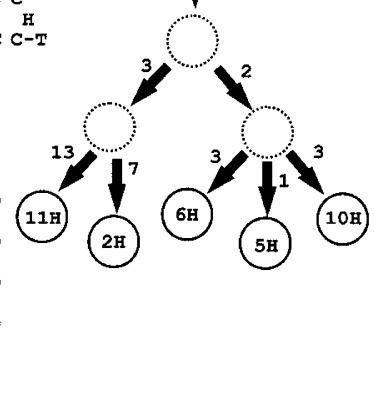

b

CDR1

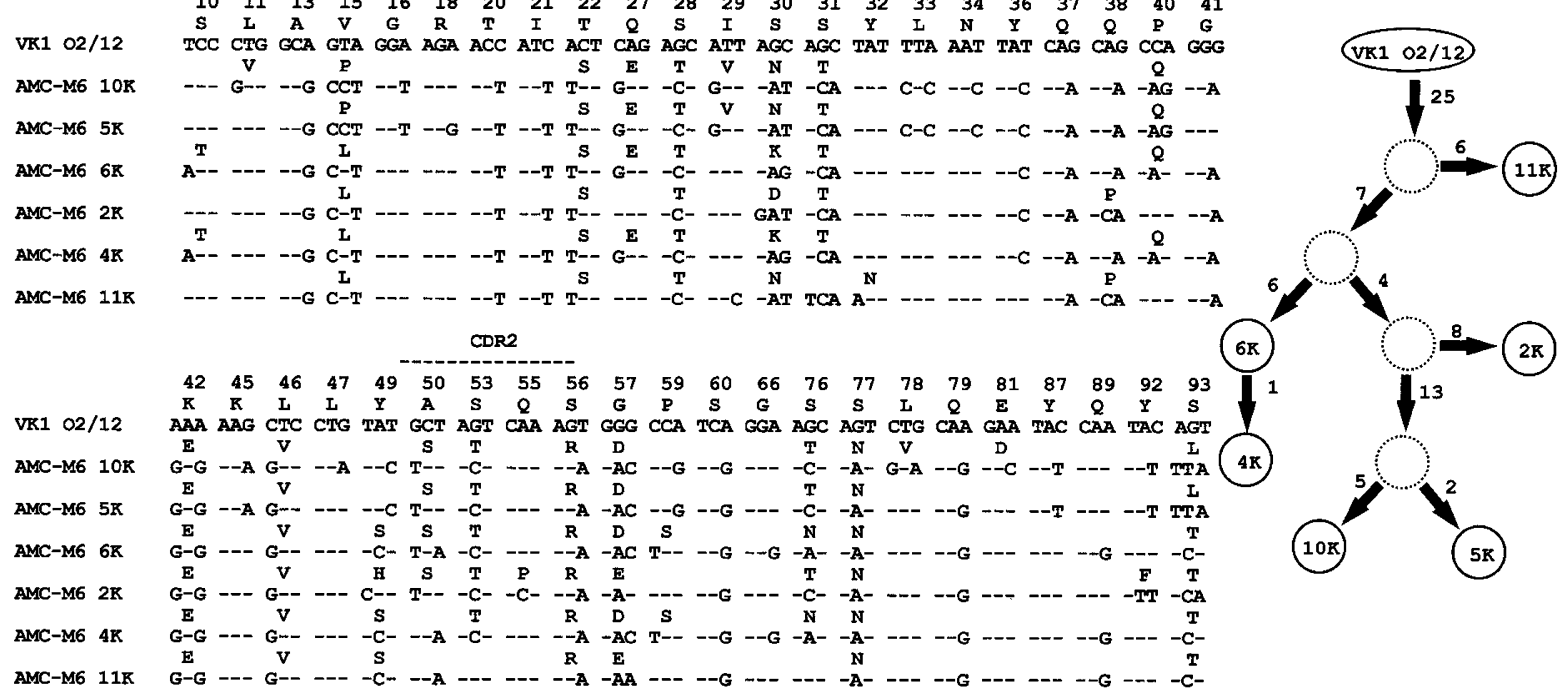

Figure 4.

Evolution of VH and VK clones from AMC-M6. Sequence alignments and genealogic trees for (a) AMC-M6 VH3-21 heavy chain and (b) VK1 02/12 kappa chain genes. The Fab nucleotide sequences were aligned with the best-matching germline genes. Only codons at which mutations occur are shown, and any amino acid changes are indicated above. The most parsimonious genealogic trees were determined on the basis of shared and unshared mutations using the PAUP program (Swofford, 1993). Fab names are shown in the circles, with $\mathrm{H}$ referring to the heavy chain and $\mathrm{K}$ referring to the kappa chain. Dotted circles refer to hypothetical intermediates. Numbers beside arrows show the minimum number of substitutions required at each step (which may include multiple changes at a single nucleotide position).

is thought to be the target of the majority of AChR antibodies in MG (Tzartos et al, 1998); although some may have a preference for the fetal isoform (Fostieri et al, 2000), they should also have been able to bind adult AChR and to compete with the anti-MIR mAb. In fact, the almost exclusive recognition of fetal, rather than adult, AChR contrasts sharply with Fabs cloned from the thymus of a more typical nonparous young female MG patient under the same conditions. In Farrar et al (1997) we obtained four distinct Fabs; three of them bound adult and fetal isoforms impartially and competed with mAbs specific for the MIR on the $\alpha$ subunits. Only the fourth, which used another VH3 gene, DP58, showed similar fetal AChR specificity to the present Fabs. In another study that also used predominantly fetal AChR for selection (Graus et al, 1997), only anti-MIR Fabs were obtained. Thus, we do not believe that the selection with ischemic muscle AChR explains the bias toward fetal AChR. Although we did not generate a library from a control thymus, in a study of Fabs derived from an MG thymoma library, we found only one with $A C h R$ reactivity but a large number binding to IFN- $\alpha$, apparently reflecting the spontaneous production of anti-IFN- $\alpha$ antibodies but not AChR antibodies by the patient's thymic lymphocytes $(H$. Shiono et al, unpublished data). Thus the selection process is antigen-specific and depends on the 
presence of the relevant heavy and light chain genes in the thymic tissue.

We had hoped to clone Fabs that inhibited fetal AChR ion channel function, because these antibodies are clearly present in the AMC-M sera (Riemersma et al, 1997) and in 5 of 12 of the parous MG women, and we found that monomeric serum Fabs retain inhibitory activity. Although the main ACh-binding sites are on the $\alpha$ subunits, they lie at the $\alpha / \delta$ and $\alpha / \gamma$ interfaces: the distinctive $\alpha / \gamma$ site of the fetal isoform seems to be the target for the inhibitory antibodies (Riemersma et al, 1997). Similar antibodies were found in one MG serum using rat fetal AChR in an early study (Weinberg and Hall, 1979), although they bound to both adult and fetal isoforms when human AChR was used (Burges et al, 1990). These inhibitory antibodies compete with ${ }^{125} \mathrm{I}-\alpha$-BuTx for binding to one of its two sites, making their detection with ${ }^{125} \mathrm{I}-\alpha$-BuTx-AChR more difficult, although we tried to overcome this difficulty by overlaying the filters with unlabeled AChR and adding ${ }^{125}$ I- $\alpha$-BuTx subsequently. However, despite their potency in causing AMC, they constitute only about $5 \%$ of the total anti-AChR antibodies in either these patients' thymic culture supernatants (not shown) or their sera (A. Vincent, unpublished calculations from data in Riemersma et al, 1997). This probably explains their rarity among our cloned Fabs.

The efficient screening and cloning of Fabs binding specifically to fetal AChR implies a striking dominance of this specificity in the AMC mothers' thymic cells. Furthermore, we found a single dominant family of clonally related $\mathrm{V} \kappa$ sequences in AMC-M6 and of $\mathrm{VH} 3$ sequences in both patients. In AMC-M2, the same clonally related $\mathrm{VH} 3-07$ sequences predominated whether they were isolated together with $\kappa$ or $\lambda$ light chain partners and irrespective of the screening procedure used (Table 2). A parallel restriction in Fabs recognizing a minority epitope, contrasting with heterogeneity of those against a dominant region, has recently been reported for thyroid peroxidase in a patient with Graves' disease (Pichuri et al, 2001). The VH3 germline genes of our two clonal families are both commonly used by normal blood B cells (de Wildt et al, 1999), as is the $V_{\kappa} 102 / 12$ that predominated in AMC-M6 and recurred in AMC-M2 (de Wildt et al, 1999; Foster et al, 1997). A PCR bias seems very unlikely because the five nonspecific Fabs isolated from our AMC-M2 VH/ $\mathrm{V}_{\kappa}$ library did not include the VH3-07, VH3-21, or $\mathrm{V}_{\kappa} 1$ 02/12 genes and $\mathrm{VH} 3$ genes are not overrepresented in Fabs cloned, using the same primers, from other MG patients against other antigens ( $Y$ Wong, N Willcox, and $A$ Vincent, unpublished observations) or from autoimmune thyroid tissue (Chazenbalk et al, 1993; Guo et al, 1999).

Because the dominant VH3-07 used by AMC-M2 was paired with so many unrelated light chains (both $\kappa$ and $\lambda$ ), its $\mathrm{VH}$ probably makes the major contribution to binding specificity, as has frequently been observed with other antibodies (Collet et al, 1992; reviewed in Dorrington and Tanford, 1970; Guo et al, 1999; Weigert and Potter, 1977; Winter et al, 1994). With AMC-M6, by contrast, the recurring usage of highly mutated and clonally related light chains in exclusive combination with the dominant $\mathrm{VH} 3-21$ suggests that they also have a major influence on specificity (as reviewed by Weigert and Potter, 1977). There are long-established precedents for that in certain heritable restricted responses in mice to well-defined epitopes (Weigert and Potter, 1977) and also in human autoantibodies (Hoet et al, 1999).

Importantly, the deduced ancestral sequence for each of the dominant families is already highly mutated (with 32, 44, and 25 shared differences from germ lines for AMC-M2 and AMC-M6 VH and AMC-M6 $V_{\kappa}$, respectively), indicating that the progenitor $B$ cells had already undergone antigen selection in GC before further refinement in the thymus. Almost all of the present sequences show multiple mutations, especially in the CDRs where R:S ratios were often high. Of particular interest is the evidence of convergent mutations in the two patients' $\mathrm{VH}$ and especially in the recurrent ${ }^{22}$ SRASET $^{28}$ sequences in $V_{\kappa}$, suggesting that these Fabs may be recognizing a dominant fetal AChR epitope. Together with the abundant mutations, the high R:S ratios in the CDRs, and the branching patterns of their evolution, these results strongly suggest that each Fab is the end-product of successive stages of antigen-driven clonal proliferation in GC, as also found after Haemophilus vaccination in subjects with preexisting B cell memory (Hougs et al, 1999). One can envisage that, over the preceding years, and four and two pregnancies, respectively, the memory B cells that were initially generated could reactivate and/or reenter GC for further rounds of mutational refinement. The striking patterns of oligoclonal evolution/diversification that we have observed in the fetal AChR-specific Fabs from both AMC mothers are very reminiscent of those noted in a mouse model with spontaneous systemic lupus erythematosus, where a surprising variety of specificities stemmed from remarkably few ancestral B cells (Shlomchik et al, 1987).

On the basis of these results, we suggest the initial immunization is by the fetus, generating a restricted group of mutated "progenitor" memory cells, possibly in lymph nodes draining the uterus. Consequently, circulating antibodies are produced against fetal AChR; they attack rare myoid cells in the thymus that express this isoform (Schluep et al, 1987), releasing antibody:AChR complexes that provoke local GC formation very efficiently (Kunkl and Klaus, 1981; MacLennan, 1994). The progenitor memory cells are attracted by the complexes trapped in these GC and undergo further rounds of mutation and selection, culminating in the expanded populations of clonally related $B$ cells and plasma cells that we have detected (Table 3, Fig. 4). Independent evidence has already strongly implicated myoid cells in GC formation in 36 EOMG thymic samples, including AMC-M2 and AMC-M6 (Roxanis et al, 2002) as well as GCs in diversification of $\operatorname{lgG}$ antibodies in MG (Sims et al, 2001).

Several autoimmune diseases show both a strong female bias and onset in early adulthood (eg, systemic 
lupus erythematosus, thyroid disease, multiple sclerosis, and EOMG); there is evidence for the importance of hormonal influences in the autoimmune response as well as potential $\mathrm{X}$ chromosome contributions in these diseases (Whitacre, 2001). Persisting fetal $\leftrightarrow$ maternal microchimerism has also been invoked because of the recent findings of fetal or maternal RNA in scleroderma lesions (discussed in Maloney et al, 1999; Nelson, 2001). There are already well-known examples of alloimmunization of mothers, for example, by fetal erythrocytes or platelets (Blanchette et al, 2000). Although it might be informative to look for allotypic variations in the AChR $\gamma$ subunit, the AChR is remarkably autoimmunogenic, even without adjuvant (Jermy et al, 1993). Although the majority of female patients with EOMG present before pregnancy, our results suggest that autoimmunization by the fetus is another possible route to maternal MG, perhaps enhanced by presentation by semiallogeneic (fetal) cells.

\section{Methods}

\section{Clinical Material}

Patient material was obtained with informed consent and Ethical Committee approval. Sera from patients with MG were collected in Professor John NewsomDavis' clinic, before thymectomy or immunosuppression, and stored at $-20^{\circ} \mathrm{C}$. Antibodies to AChR were measured as previously described (Riemersma et al, 1997; Vincent et al, 1995). AMC-M2 and AMC-M6 (described in Jacobson et al, 1999a; Riemersma et al, 1997) had had four and two babies, respectively, with severe AMC (fatal in all but one); but the diagnosis of maternal MG was made only after the birth of the AMC babies. After therapeutic thymectomy and immunosuppressive therapies for their MG, and plasma exchange during pregnancy, both mothers have subsequently had successful pregnancies with minimally affected babies (our unpublished observations). Thymus cell suspensions were prepared and cryopreserved according to the method of Willcox et al (1983). From both patients, these cells spontaneously produced high levels of anti-AChR antibodies in culture that were reduced by pokeweed mitogen, typical of plasma cell behavior (Willcox et al, 1983); these antibodies showed a strong preference for fetal AChR and also inhibited its ion channel function (not shown), as did serum antibodies from AMC-M2 (Riemersma et al, 1997) and AMC-M6 (Fig. 1).

\section{Measurement of Inhibition of AChR Function in TE671 Cell Line}

We measured AChR function in TE671 cells that express only fetal AChR, as previously described (Riemersma et al, 1997). Carbachol-induced ${ }^{22} \mathrm{Na}^{+}$ flux was measured over 1 minute, and the internalized ${ }^{22} \mathrm{Na}^{+}$was counted on a Packard Auto-Gamma counter. The inhibitory effect of the sera was tested by incubating the cells with $25 \mu \mathrm{l}$ of serum in $500 \mu \mathrm{l}$ of Hepes Locke buffer (ie, 1:20) for 30 minutes. The results are expressed as percent inhibition, with 0\% being the cpm in Hepes Locke buffer alone and 100\% inhibition being the cpm in cells tested in the presence of $1 \mu \mathrm{g} / \mathrm{ml}$ of the antagonist $\alpha$-BuTx. Those sera producing more than $50 \%$ inhibition were then retested at higher dilutions, and the results are presented as percent inhibition per microliter of serum.

\section{Combinatorial Ig Gene Library Construction}

The Fab library was made from cDNA after reversetranscription from mRNA obtained from thymic cells (Farrar et al, 1997). We used an antisense primer for an IgG1 CH1 sequence (almost identical to its IgG3 homolog; Kabat et al, 1991) to amplify VH chain cDNA by PCR in combination with a panel of sense oligonucleotide primers designed to include $\mathrm{VH} 1-\mathrm{VH} 6$ gene families: further panels amplified the $V_{\kappa}$ or $V \lambda$ gene families, as described by Farrar et al (1997). The PCR products were ligated into Immunozap $\mathrm{H}$ or $\mathrm{L}$ bacteriophage vectors (Stratagene, La Jolla, California). Subsequently, the heavy and light chain DNAs were ligated into Immunozap to yield combinatorial libraries, as detailed previously (Chazenbalk et al, 1993; Farrar et al, 1997).

\section{Screening the Library for AChR-Binding Fabs}

Positive clones were identified essentially as in Farrar et al (1997). Muscle extracts from denervated muscles were labeled with 2 nм ${ }^{125}$ I- $\alpha$-BuTx (Amersham International, Buckinghamshire, United Kingdom; specific activity $2000 \mathrm{Ci} / \mathrm{mmol}$ ) and used to screen the unamplified combinatorial library in XL1-Blue cells by filterlift assays. Positive plaques were identified by autoradiography, cloned to homogeneity, and the heavy and light chain genes were sequenced in both directions by the dideoxy chain termination method (Sanger et al, 1977). To obtain soluble Fabs, the XL1-Blue cells were induced with $1 \mathrm{~mm}$ isopropyl-thio-galacto-pyranoside (Sigma, St. Louis, Missouri) overnight. The cells were then pelleted and freeze/thawed in $10 \mathrm{~mm}$ Tris buffer (pH 8.0) containing protease inhibitors (Farrar et al, 1997). The suspension was sonicated and cleared by centrifugation, to leave a Fab-containing lysate.

\section{Characterizing Fab Reactivity with AChR}

The lysates were used without further purification. They were incubated with AChR (either from muscle extracts, from TE671 cells, or from a transfected subline that expresses predominantly adult AChR; Beeson et al, 1996) labeled with ${ }^{125} \mid-\alpha$-BuTx. After 2 hours at $20^{\circ} \mathrm{C}$, carrier normal human serum was added plus a goat anti-human IgG (Lawrance Laboratories, Perth, Western Australia), which precipitated the Fab-AChR complexes efficiently. Competition with mAbs (Jacobson et al, 1999b) was measured by preincubating the ${ }^{125} \mathrm{I}-\alpha$-BuTx-AChR with $50 \mu \mathrm{l}$ of each Fab overnight at $4^{\circ} \mathrm{C}$ and then adding excess $(0.1 \mu l$ of ascites) of each mAb (Farrar et al, 1997). Sheep antibody to mouse IgG (which did not precipitate human Fabs) was then added to precipitate 
mAb-AChR complexes. All results were compared with precipitation in the presence of a control Fab that did not bind AChR and are expressed as the percent inhibition by each Fab of the binding of the indicated mAb (Whiting et al, 1986).

\section{Bioinformatics}

Sequences were compared with the human VBASE directory of immunoglobulin genes (Tomlinson et al, 1997) using DNAPLOT (W. Müller, Institut für Genetik, Köln, Germany) to determine the best matching germline V-gene segments. Sequences with the same gene rearrangement and common CDR3s were judged to be clonally related. The numbers of somatic mutations over the $\mathrm{VH}$ and $\mathrm{V} \kappa$ regions were determined, and $\mathrm{R}: \mathrm{S}$ ratios were calculated for FWR and CDR. Amino acid numbering and FWR and CDR positions were previously defined by Kabat et al (1991). Genealogic trees were constructed for sets of related genes by analysis of shared and unshared mutations using phylogenetic analysis using parsimony (PAUP) (Swofford, 1993). Independent genes were also compared for the occurrence of convergent mutations.

\section{Acknowledgement}

We are grateful to Drs. Sandra MacLachlan and Basil Rapoport for their help in establishing the Fab libraries, to the patients for their cooperation, and to Prof. John Newsom-Davis for access to the clinical material.

\section{References}

Beeson D, Jacobson L, Newsom-Davis J, and Vincent A (1996). A transfected human muscle cell line expressing the adult subtype of the human muscle acetylcholine receptor for diagnostic assays in myasthenia gravis. Neurology 47:1552-1555.

Blanchette VS, Johnson J, and Rand M (2000). The management of alloimmune neonatal thrombocytopenic purpura. Baillère's Clin Haematol 13:365-390.

Bofill M, Janossy G, Willcox N, Chilosi M, Treijdosiewicz LK, and Newsom-Davis J (1985). Microenvironments in the normal and myasthenia gravis thymus. Am J Pathol 119:462-473.

Burges J, Wray DW, Pizzighella S, Hall Z, and Vincent A (1990). A myasthenia gravis plasma immunoglobulin reduces miniature endplate potentials at human endplates in vitro. Muscle Nerve 13:407-413.

Chazenbalk GD, Portolano S, Russo D, Hutchison JS, Rapoport B, and McLachlan S (1993). Human organ-specific autoimmune disease: Molecular cloning and expression of an autoantibody gene repertoire for a major autoantigen reveals an antigenic immunodominant region and restricted immunoglobulin gene usage in the target organ. $\mathrm{J}$ Clin Invest 92:62-74.

Collet TA, Roben P, O'Kennedy R, Barbas CF, and Burton DR (1992). A binary plasmid system for shuffling combinatorial antibody libraries. Proc Natl Acad Sci USA 89:10026-10030.

de Wildt RMT, Hoet RMA, van Venrooij WJ, Tomlinson IM, and Winter G (1999). Analysis of heavy and light chain pairings indicates that receptor editing shapes the human antibody repertoire. J Mol Biol 285:895-901.
Dorrington KJ and Tanford C (1970). Molecular size and conformation of immunoglobulins. Adv Immunol 12:333-381.

Drachman DB (1994). Myasthenia gravis. N Engl J Med 330:1797-1810.

Farrar J, Portolano S, Willcox N, Vincent A, Jacobson L, Newsom-Davis J, Rapoport B, and McLachlan SM (1997). Diverse Fab specific for acetylcholine receptor epitopes from a myasthenia gravis thymus combinatorial library. Int Immunol 9:1311-1318.

Foster SJ, Brezinschek H-P, Brezinschek RI, and Lipsky PE (1997). Molecular mechanisms and selective influences that shape the kappa gene repertoire of $\operatorname{lgM}^{+} B$ cells. J Clin Invest 99:1614-1627.

Fostieri E, Beeson D, and Tzartos SJ (2000). The conformation of the main immunogenic region on the $\alpha$-subunit of muscle acetylcholine receptor is affected by neighboring receptor subunits. FEBS Lett 481:127-130.

Graus YF, de Baets MH, Parren PWHI, Berrih-Aknin S, Wokke J, van Breda Vriesman PJ, and Burton DR (1997). Human anti-nicotinic acetylcholine receptor recombinant Fab fragments isolated from thymus-derived phage display libraries from myasthenia gravis patients reflect predominant specificities in serum and block the action of pathogenic serum antibodies. J Immunol 158:1919-1929.

Guo J, Wang Y, Jaume JC, Rapoport B, and McLachlan S (1999). Rarity of autoantibodies to a major autoantigen, thyroid peroxidase, that interact with denatured antigen or with epitopes outside the immunodominant region. Clin Exp Immunol 117:19-29.

Hall JM, Lingenfelter P, Adams SL, Lasser D, Hansen JA, and Bean MA (1995). Detection of maternal cells in human umbilical cord blood using fluorescence in situ hybridization. Blood 86:2829-2832.

Hall JG and Vincent A (2001). Arthrogryposis. In: Jones HR Jr, Darras BT, and De Vivo DC, editors. Neuromuscular disorders of infancy, childhood and adolescence. Woburn, MA: Butterworth Heinemann.

Heidenreich F, Vincent A, Willcox N, and Newsom-Davis J (1988). Anti-acetylcholine receptor antibody specificities in serum and in thymic culture supernatants from myasthenia gravis patients. Neurology 38:1784-1788.

Hesselmans L, Jennekens F, van den Oord C, Veldman H, and Vincent A (1993). Development of innervation of skeletal muscle fibers in man: Relation to acetylcholine receptors. Anat Rec 236:553-562.

Hoet RMA, Pieffers M, Stassen MHW, Raats J, de Wildt R, Pruijn GJM, van den Hoogen F, and van Venrooij WJ (1999). The importance of the light chain for the epitope specificity of human anti-U1 small nuclear RNA autoantibodies present in systemic lupus erythematosus patients. J Immunol 163:3304-3312.

Hougs L, Juul L, Ditzel HJ, Heilmann C, Svejgaard A, and Barington T (1999). The first dose of a Haemophilus influenzae b conjugate vaccine reactivates memory B cells: Evidence for extensive clonal selection, intraclonal affinity maturation, and multiple isotype switches to IgA2. J Immunol 162:224-237.

Jacobson L, Beeson D, Tzartos S, and Vincent A (1999b). Monoclonal antibodies raised against human acetylcholine receptor bind to all five subunits of the fetal isoform. $J$ Neuroimmunol 98:112-120. 
Jacobson L, Polizzi A, Morriss-Kay GM, and Vincent A (1999a). An animal model of antibody-mediated neurodevelopmental disease: Arthrogryposis multiplex congenita caused by antibodies to fetal acetylcholine receptor. J Clin Invest 103:1031-1038.

Jermy A, Beeson D, and Vincent A (1993). Pathogenic anti-(mouse) acetylcholine receptor induced in BALB/C mice without adjuvant. Eur J Immunol 23:973-976.

Kabat EA, Wu TT, Perry HM, Gottesman KS, and Foeller C (1991). Sequences of proteins of immunological interest, vol 2. Bethesda, MD: National Institutes of Heath.

Kornstein MJ, Brooks JJ, Anderson AO, Levinson AI, Lisak $\mathrm{RP}$, and Zweiman B (1984). The immunohistology of the thymus in myasthenia gravis. Am J Pathol 117:184-194.

Kunkl A and Klaus GGB (1981). The generation of memory cells IV. Immunisation with antigen-antibody complexes accelerates the development of B memory cells, the formation of germinal centres and the maturation of antibody affinity in the secondary response. Immunology 43:371-378.

MacLennan ICM (1994). Germinal centres. Ann Rev Immunol 12:117-139.

Maloney S, Smith A, Furst DE, Myerson D, Rupert K, Evans PC, and Nelson JL (1999). Microchimerism of maternal origin persists into adult life. J Clin Invest 104:41-47.

Nelson JL (2001). HLA relationships of pregnancy, microchimerism and autoimmune disease. J Reprod Immunol 52:77-84.

Pichuri P, Guo J, Rapoport B, and McLachlan S (2001). Human monoclonal autoantibodies to B-cell epitopes outside the thyroid peroxidase autoantibody immunodominant region. Thyroid 11:301-313.

Polizzi A, Huson SM, and Vincent A (2000). Teratogen update: Maternal myasthenia gravis as a cause of congenital arthrogryposis. Teratology 62:332-341.

Riemersma S, Vincent A, Beeson D, Newland C, Hawke S, Vernet der Garabedian B, Eymard B, and Newsom-Davis J (1997) Association of arthrogryposis multiplex congenita with maternal antibodies inhibiting fetal acetylcholine receptor function. J Clin Invest 98:2358-2363.

Roxanis I, Micklem K, McConville J, Newsom-Davis J, and Willcox N (2002). Thymic myoid cells and germinal center formation in myasthenia gravis: Possible roles in pathogenesis. J Neuroimmunol 125:185-197.

Sanger F, Nicklen S, and Coulson AR (1977). DNA sequencing with chain-terminating inhibitors. Proc Natl Acad Sci USA 74:5463-5467.

Schluep M, Willcox N, Vincent A, Dhoot GK, and NewsomDavis J (1987). Acetylcholine receptors in human myoid cells in situ: An immunohistological study. Ann Neurol 22:212-222.

Serrano MPI, Cardona A, Vernet der Garabedian B, Bach J-F, and Pléau J-M. (1994). Nucleotide sequences of variable regions of a human anti-acetylcholine receptor autoantibody derived from a myasthenic patient. Mol Immunol 31:413417.

Shlomchik MJ, Marshak-Rothstein A, Wolfowicz CB, Rothstein TL, and Weigert MG (1987). The role of clonal selection and somatic mutation in autoimmunity. Nature 328:805-811.

Sims GP, Shiono H, Willcox N, and Stott DI (2001). Somatic hypermutation and selection of B cells in thymic germinal centers responding to acetylcholine receptor in myasthenia gravis. J Immunol 167:1935-1944.
Swofford DL (1993). PAUP: Phylogenetic analysis using parsimony, Version 3.1. Champaign, IL: Natural History Survey.

Tomlinson IM, Williams SC, Ignatovich O, Corbett SJ, and Winter G (1997). Human VBASE directory of immunoglobulin genes. Cambridge, UK: MRC Centre for Protein Engineering.

Tzartos SJ, Barkas T, Cung MT, Mamalaki A, Marraud M, Orlewski P, Papanastasiou D, Sakarellos C, Sakarellos-Daitsiotis M, Tsantili $\mathrm{P}$, and Tsikaris V (1998). Anatomy of the antigenic structure of a large membrane autoantigen, the muscle-type nicotinic acetylcholine receptor. Immunol Rev 163:89-120.

Unwin N (2000). Nicotinic acetylcholine receptor and the structural basis of fast synaptic transmission. Phil Trans $R$ Soc Lond B Biol Sci 355:1813-1829.

Vernet der Garabedian B, Lacokova M, Eymard B, Morel E, Faltin M, Zajac J, Sadovsky O, Dommergues M, Tripon P, and Bach JF (1994). Association of neonatal myasthenia gravis with antibodies against the fetal acetylcholine receptor. J Clin Invest 94:555-559.

Vincent A, Buckley C, Dalton P, Clover L, Liguori R, Montagna P, McConville J, and Hoch W (2001). New antibodies to neuronal and muscle antigens. In: Vincent A and Martino G, editors. Autoantibodies in neurological diseases. Milan: Springer-Verlag, 19-27.

Vincent A, Newland C, Brueton L, Beeson D, Riemersma S, Huson SM, and Newsom-Davis J (1995). Arthrogryposis multiplex congenita with maternal autoantibodies specific for a fetal antigen. Lancet 346:24-25.

Vincent A and Newsom-Davis J (1985). Acetylcholine receptor antibody as a diagnostic test for myasthenia gravis: Results in 153 validated cases and 2967 diagnostic assays. J Neurol Neurosurg Psychiatry 48:1246-1252.

Vincent A, Whiting PJ, Schluep M, Heidenreich F, Lang B, Roberts A, Willcox N, and Newsom-Davis J (1987). Antibody heterogeneity and specificity in myasthenia gravis. Ann NY Acad Sci 505:106-120.

Weigert M and Potter M (1977). Antibody variable region genetics: Summary and abstracts of homogeneous immunoglobulin workshop. Immunogenetics 4:401-435.

Weinberg CB and Hall ZW (1979). Antibodies from patients with myasthenia gravis recognize determinants unique to extrajunctional acetylcholine receptors. Proc Natl Acad Sci USA 76:504-508.

Whitacre CC (2001). Sex differences in autoimmunity. Nat Immunol 2:777-780.

Whiting PJ, Vincent A, and Newsom-Davis J (1986). Myasthenia gravis: Monoclonal anti-human acetylcholine receptor antibodies used to analyze antibody specificities and responses to treatment. Neurology 36:612-617.

Willcox HNA, Newsom-Davis J, and Calder LR (1983). Greatly increased autoantibody production in myasthenia gravis by thymocyte suspensions prepared with proteolytic enzymes. Clin Exp Immunol 54:378-386.

Willcox N and Vincent A (1988). Myasthenia gravis as an example of organ-specific autoimmune disease. In: Bird $\mathrm{G}$ and Calvert JE, editors. B lymphocytes in human disease. Oxford: Oxford Medical Publications, Oxford University Press.

Winter G, Griffiths AD, Hawkins RE, and Hoogenboom HR (1994). Making antibodies by phage display technology. Ann Rev Immunol 12:433-455. 